\title{
DESLOCAMENTOS IDENTITÁRIOS A PARTIR DO SERTÃO NO ROMANCE GALILEIA DE RONALDO CORREIA DE BRITO
}

Daniela Barbosa de Oliveira (UFJF)

RESUMO: O texto aborda questões relacionadas ao hibridismo cultural e ao trânsito de identidades na pós-modernidade a partir da trajetória de deslocamentos, entre sertão nordestino e cosmopolitismo, dos personagens do romance Galileia (2008), de autoria do escritor cearense Ronaldo Correia de Brito. Como principais contributos teóricos foram utilizadas as obras de Hall (2002) e Bhabha (1998).

Palavras-chave: Identidade; sertão; deslocamentos.

ABSTRACT: The text addresses issues related to cultural hybridity and to the transit of identities in postmodernity from the trajectory of the displacements, between the northeastern backlands and cosmopolitanism, of the characters of the novel Galileia (2008), written by Ronaldo Correia de Brito. The main theoretical contributions were the works of Hall (2002) and Bhabha (1998).

Keywords: Identity; backlands; displacements.

A aceleração de um efetivo projeto de industrialização no Brasil data das primeiras décadas do século XX. No entanto, já no último quartel do século XIX era possível observar um crescente fluxo migratório originado nas regiões interioranas e rurais do país, em direção à prosperidade econômica e às oportunidades de ascensão social alardeadas pelo cosmopolitismo do eixo Sul-Sudeste. Em conformidade com dados estatísticos, o supracitado êxodo rural intensificouse vertiginosamente com o passar dos anos, de modo que, 
já na década de 1930 os migrantes nacionais eram maioria em relação aos imigrantes estrangeiros e, por volta de 1970, mais de 40 milhões de indivíduos haviam deixado o interior, fazendo com que a população urbana, pela primeira vez, superasse numericamente a população rural (IBGE, 2016).

Contudo, para além de transformações sociais quantitativas, todo movimento migratório traz consigo um deslocamento de contextos estruturais subjacentes aos sujeitos em trânsito. Trata-se de tradições, costumes, linguagens, sentidos e histórias características do lugar de origem. Transladados para um novo ambiente, estes elementos, em contato com seus equivalentes locais, fazem emergir uma estrutura social multifacetada, resultante da recombinação de territorialidades e identidades.

O romance Galileia (2008), de autoria do médico e escritor cearense Ronaldo Correia de Brito, expõe os processos de hibridação cultural decorrentes do choque entre a tradição rural sertaneja e nordestina no Brasil e aspectos da lógica urbana moderna, impactando fortemente o reconhecimento identitário das personagens. Nascido na cidade de SaboeiroCE na década de 1950, o autor é também um migrante, mudouse ainda jovem para Recife, onde se formou na Faculdade de Medicina pela Universidade Federal de Pernambuco. 
A trajetória de deslocamento, bem como a formação médica, projetava uma aparente ancoragem geográfica e profissional ao cearense. No entanto as memórias da infância sertaneja fizeram-no "um andarilho em volta de si mesmo" (PIEIRO, 2009, p.2), de modo que a incursão pelo universo literário foi a responsável não apenas por diversificar a carreira do jovem clínico, mas sobretudo por guiar sua pena pelos caminhos de um sertão fixado em lembranças ambivalentes.

Contista consagrado pelas coletâneas Faca (2003) e $O$ Livro dos Homens (2005), foi com Galileia que o escritor logrou alcançar prestígio nacional, inclusive, conquistando o Prêmio Cidade de São Paulo em 2009. A obra dialoga com o conjunto de sua produção na medida em que a paisagem sertaneja, para além de pano de fundo da narrativa, transmuta-se em personagem central da trama, determinando ações, inspirando emoções contraditórias e, sobretudo, contrapondo memórias de um passado de tradições regionais com os aspectos totalizantes de uma irremediável modernidade que se impõe aos seus contornos. Assim, na narrativa de Brito, a modernidade atravessa o território sertanejo pela recorrência às imagens de progresso e desenvolvimento técnico, bem como pela secularização das relações sociais, agora ressignificadas e desmitificadas. 
No entanto, ao propor-se a tarefa de explorar a questão regional, ambientada no território sertanejo e rural nordestino, em sua relação com a parte urbana do país, Ronaldo Correia de Brito pretende mais que apenas fazer convergir, mecanicamente, localismo e cosmopolitismo, mas também transgredir a tradicionalidade dos discursos sobre o sertão, "evitando tornar-se continuador de uma vertente regionalista [...], até porque este lugar sem limites já não é mais o mesmo" (PIEIRO, 2009, p.5). Neste sentido, embora resgate uma textualidade elaborada sobre o Nordeste, e no Nordeste, haja vista que muitas das problemáticas levantadas por este discurso ainda reverberem na atualidade, a produção de Ronaldo Correia de Brito questiona muitos dos alicerces e pressupostos cristalizados pela geração regionalista de 1920-30.

Os costumes e traços etnográficos relacionados ao Nordeste brasileiro, por exemplo, também povoam as páginas da produção do escritor cearense contemporâneo, mas no sentido de serem confrontados com as experiências urbanas e modernas de seus personagens. De acordo com Silva (2012, p.138), o romance Galileia, de maneira particular, se difere das narrativas do início do século passado por "não almejar a defesa da região, não cantar as glórias 
de um passado, nem reivindicar mudanças sociais". Brito estaria, portanto, em consonância com o que Karl Shollammer (2001, Apud SILVA, 2012, p.138) observa a respeito da produção literária contemporânea, na qual a questão regional aparece revestida de novas roupagens e torna-se "palco da tensão entre campo e cidade, entre a herança rural e o futuro apocalíptico das grandes metrópoles". O próprio escritor ressaltou por diversas vezes em entrevistas sua recusa em adequar-se a fórmulas literárias consagradas na construção de seu espaço regional, evidenciando um sertão que não está parado no tempo, mas em constante transformação:

Escrevo sobre um sertão invadido pelas cidades. E sobre cidades arruinadas pela ruptura com o sertão. Meus personagens, apesar da paisagem desértica, são neuroticamente urbanos. O que é o sertão, você sabe? Eu juro que não sei. No entanto, ele existe. $\mathrm{E}$ eu nada mais faço que procurálo (BRITO, Apud MELO, 2006)

O meu sertão é complexamente urbano. Seus personagens [...] sofrem uma doença grave, que mina a saúde mental de todos eles: adequar o mundo arcaico que herdaram, ao mundo globalizado em que se viram inseridos de forma brutal, num intervalo de tempo muito curto (BRITO, Apud PEREIRA, 2009)

Em Galileia, a imagem do passado, outrora seguro e hegemônico, que esvaece em novas e incompreensíveis 
paisagens é fulcral e recorrente. Três são os personagens que conduzem o leitor por este percurso, que na narrativa de Brito, se materializa em uma viagem de retorno dos irmãos Ismael e Davi e do primo (e narrador) Adonias à fazenda Galileia. Por ocasião daquele que poderia vir a ser o último aniversário do avô, já bastante velho e doente, os três se encontram obrigados a revisitar a região na qual haviam passado a juventude. Embora compartilhem o mesmo local de infância, estes personagens retornam ao sertão, vindos de destinos bastante diferentes como São Paulo, Recife e a distante e fria Noruega.

Já nas primeiras páginas do romance, Adonias demonstra seu espanto com a nova configuração sertaneja com a qual se depara enquanto guia a camioneta, acompanhado dos primos, rumo ao interior mais longínquo do Ceará.

Imagino a casa dos meus avós derrubada por tratores, dando lugar a uma rodovia. $O$ barulho forte das máquinas e as luzes dos faróis me deixam a impressão de que estou noutro planeta. Mas não estou. $O$ sertão continua na minha frente, nos lados, atrás de mim. $O$ asfalto fede. Já chorei por causa dessa ferida preta, cortando as terras. Agora me distraio com os carros que passam.

Onde estão os caminhos abertos pelos antigos, os que elegeram essa terra para morar, trazendo rebanhos e levantando currais? [...] Que fim levaram as árvores de porte? Só avisto deserto cinza, sem um único verde (BRITO, 2008, p.8) 
O estranhamento que inicialmente se apresenta apenas pelo conteúdo material das paisagens postas em comparação, logo se mostra um sentimento muito mais profundo. Adonias, que compartilha boa parte da biografia de Ronaldo Correia de Brito, podendo ser interpretado como uma espécie de alter-ego do autor, é médico criado em Recife desde os cinco anos de idade. Gosta de identificar-se como sujeito profundamente cosmopolita, tendo, portanto, superado suas raízes sertanejas. Tamanha convicção cai por terra, no entanto, quando o protagonista vê-se confrontado com as memórias trazidas à tona pelo percurso até Galileia.

Tal qual o intelectual Stuart Hall, nascido na Jamaica e atualmente radicado na Inglaterra, que declara sentir-se um indivíduo duplamente estrangeiro, posto que "conheço intimamente os dois lugares, mas não pertenço a nenhum" (HALL, 2002, p.415), Adonias também enfrenta um inesperado conflito no campo das identidades, que se mostram múltiplas, entremeadas por territórios e temporalidades sobrepostas.

Terra de ninguém, um espaço mal definido entre campo e cidade. Possuo referências do sertão, mas não sobreviveria muito tempo por aqui. Criei-me na cidade, mas também não aprendi a ginga e o sotaque urbanos. Aqui ou lá me sinto estrangeiro (BRITO, 2008, p.159) 
De maneira semelhante, Davi, primo mais novo de Adonias, relata as contradições de uma vivência de trânsito cultural. Vivendo definitivamente nos Estados Unidos, Davi pode ser considerado o mais rebelde entre os três viajantes, além de nutrir certo ressentimento para com sua vivência sertaneja. A suspeita, (não confirmada no romance) de um abuso sexual durante a infância, parece ter feito com que o jovem músico buscasse noutros espaços seus elementos identitários, embora ao final da narrativa assuma que em todas as viagens que realizou tenha experimentado o sentimento agridoce da solidão. Em seu retorno à terra natal reflete,

eu contemplo um território desconhecido, mas meu corpo é o mesmo, e ele mantém a referência de uma paisagem interna [...] Sentia-me uma escultura fora do lugar de seu museu de origem, em exposição itinerante por outras galerias, deslocado, sem foco (BRITO, 2008, p.196)

Claramente, o conflito interno vivenciado por estas personagens está alicerçado na convergência de identidades diferenciadas, que justapostas revelam indivíduos culturalmente híbridos. Tradicionalmente a noção de identidade esteve ligada à concepção de um ser unificado, que permitisse "que o indivíduo se localize em um sistema 
social e seja localizado socialmente" (CUCHE, 2002 Apud SILVA JR., 2014, p.104). Entretanto, os estímulos e desdobramentos de um mundo globalizado, sobretudo no que tange ao nomadismo moderno, fizeram com que os estudos da cultura buscassem novas estratégias de interpretação e redefinição de temas como comunidade, identidade e nação. $\mathrm{Na}$ contracorrente de teorias essencialistas, Stuart Hall (2003), enfatiza que a pós-modernidade promove a construção de identidades inevitavelmente impuras, tendo em vista a condição diaspórica dos sujeitos. Evocando os preceitos difundidos por Jacques Derrida, para Hall, "as comunidades migrantes trazem as marcas da diáspora, da 'hibridação' e da différance em sua própria constituição" (HALL, 2003 Apud COSER, 2005, p.172). Neste contexto, não seria mais possível operar sob a noção de comunidade ou de nação baseada em fronteiras fixas e rígidas, haja vista que embora forças dominantes ligadas ao mercado capitalista busquem uma homogeneização cultural segregadora, capaz de demarcar lugares sociais únicos, outros processos estão sutilmente desestabilizando os modelos ocidentais, de modo a forçar adaptações no interior da própria globalização, assentadas sob a ideia de alteridade.

Quando tratamos deste movimento de desestabilização do discurso hegemônico a respeito das relações entre 
os aspectos regional e cultural, estamos inevitavelmente tocando a oposição entre o central e o periférico, o dominador e o subalterno, o colonizador e o colonizado. De acordo com Homi Bhabha (1998), a superação destes pares dicotômicos, e a consequente defesa de um terceiro espaço, mais fluído e ambivalente, no interior do qual as relações contemporâneas são construídas, é de extrema importância para a compreensão da mutabilidade identitária contemporânea, bem como da eterna incompletude dos sujeitos na pós-modernidade. Para o autor, em comparação com delimitações espaciais paradigmáticas, este "local da cultura" pode ser definido como:

Uma forma de vida mais complexa que a "comunidade", mais simbólica que a "sociedade", mais conotativa que "país", menos patriótica que a pátrie, mais retórica que a razão do Estado, mais mitológica que a ideologia, menos homogênea que a hegemonia, menos centrada que o cidadão, mais coletiva que o "sujeito" (BHABHA, 1998, p.99)

Em última instância, o local da cultura se realiza pelo deslocamento migratório, em um processo que Bhaha (1998) chamou perspicazmente de DissemiNação, um jogo de expressões que aponta para a fragmentação das nações modernas, entendidas por suas descontinuidades e não mais por uma narrativa pretensamente unitária. 
Não obstante Hall e Bhabha apoiarem suas contribuições no contexto do que chamamos de estudos pós-coloniais, com ênfase, sobretudo, na emancipação dos povos que estiveram sob a tutela colonial nas regiões do Caribe, África e Índia, o conjunto de suas reflexões pode ser aplicado para o entendimento dos movimentos migratórios internos, como é o caso da experiência diaspórica nordestina no Brasil. Sobre este contexto, Mondardo (2010) afirma que os migrantes nacionais-regionais desenvolvem

No interior de um processo de adaptação ao novo contexto socioespacial, estratégias, sendo, uma delas a necessidade de trânsito identitário por e entre territórios culturais distintos sejam econômicos, políticos e culturais. Essa identidade em trânsito é, por isso, para os migrantes desse período da globalização, transitória, multi e até mesmo transterritorial (MONDARDO, 2010, p. 7)

Tal processo de adaptação e negociação no trânsito entre diferentes espaços está definitivamente presente no percurso do protagonista de Galileia. Após a experiência de retorno a um sertão que acreditava estar superado, em sua nova vida citadina na capital de Pernambuco, Adonias conclui estar equivocado, admitindo que "o sertão a gente traz nos olhos, no sangue, nos cromossomos. É uma doença sem cura" (BRITO, 2008, p. 9). Não era, portanto, nem sertanejo, 
nem cosmopolita, criou para si um terceiro lugar, nos moldes do que propõe Bhabha, híbrido e desafiador dos modelos identitários cristalizados.

Ao contrário de Adonias, que buscou um distanciamento voluntário (e ineficiente) de suas raízes rurais e sertanejas, o primo Ismael possui uma trajetória distinta. Filho bastardo, adotado pelo avô, é o único dentre os três viajantes para o qual o deslocamento espacial e cultural apresentou-se não como opção, mas como necessidade inconteste. Sofreu a perseguição silenciosa dos membros mais tradicionalistas da família por sua condição de filho ilegítimo que carregava nas veias o sangue dos índios Kanela, além da desconfiança, igualmente velada, de estupro contra Davi, seu meioirmão. Não obstante ter alcançado sucesso profissional no Velho Mundo, carregava consigo o constante sentimento do outsider, a completa ausência de pertencimento. Nem indígena, nem sertanejo e tampouco europeu, Ismael surpreende ao abolir todas as classificações de fronteira espaciais, traçando paralelos impensáveis entre os contextos de suas vivências:

A Noruega é um sertão a menos trinta graus. As pessoas de lá também são silenciosas, hospitaleiras e falam manso. Habituaram-se aos desertos de gelo, como nós à caatinga [...] as pessoas são as mesmas em qualquer latitude. (BRITO, 2008, p.73) 
As pessoas são as mesmas, na medida em que estão vulneráveis à ação de forças culturais múltiplas em qualquer ambiente em que circulem. Não se trata de uma proposta de unificação de identidades, pelo contrário, se trata da completa ausência de hierarquização entre estes variados agentes culturais. Percebe-se na narrativa de Ronaldo Correia de Brito, portanto, uma noção rizomática de identidade em conformidade, com a interpretação de Édouard Glissant sobre os conceitos Raiz única e Rizoma elaborados por Deleuze \& Guattari. Nesse sentido, há a valorização do pensamento que se desdobra em várias raízes, sem que exista a sobreposição de uma sobre a outra, em oposição a um pensamento unitário supostamente generalizável a todos os indivíduos.

Para Glissant, a questão atual colocada às culturas particulares é a de como renunciar à mentalidade e ao imaginário movidos pela concepção de uma "identidade-raiz única", para entrar na "Identidade-Relação", que é "raiz-rizoma", que vai ao encontro de outras raízes (ROCHA, 2009, p. 01)

O pensamento-rizoma aparece em Galileia não apenas na confluência de múltiplas identidades para a formação de indivíduos e espacialidades multiculturais, mas também na emergência de manifestações sincréticas, nas quais vozes subalternizadas aproveitam-se de interstícios do poder 
hegemônico para expor suas próprias noções de cultura. O catolicismo tão típico na caracterização das sociedades sertanejas, por exemplo, aparece no romance de forma dessacralizada e parodiada justamente pelo membro mais antigo da família Rego Castro. A própria fazenda Galileia faz referência à região de Israel, sagrada para o cristianismo. E o patriarca Raimundo Caetano vai ainda mais longe em suas alusões bíblicas, nomeando boa parte de seus descendentes com personagens retirados do Antigo Testamento, entre eles "Davi”, “Elias”, “Josafá”, “Esaú e Jacó”. Paralelamente a esta tão anunciada devoção, Raimundo mesclava sua fé cristã aos costumes religiosos locais, praticando uma espécie de catolicismo pagão (SILVA, 2012), em um significativo exemplo do hibridismo cultural teorizado por García Canclini (2003).

Sempre rezou um terço ao acordar, mas também oferecia fumo à Caipora, quando caçava. Protegia a casa dos maus-olhados atirando sal grosso nos seus quatro cantos. Os umbigos dos nove filhos legítimos foram enterrados na porteira do curral, para que não abandonassem a terra, e todos se tornassem fazendeiros criadores de gado (BRITO, 2008, p.23)

O feitiço de Raimundo Caetano, entretanto, mostrouse definitivamente ineficaz. Dos nove filhos, uma minoria permaneceu em Galileia, os demais ou morreram ou optaram 
por abandonar o sertão, destino também de muitos de seus netos. Tratam-se de sujeitos deslizantes, líquidos, como nos propõem Bauman (1999), "aves de arribação", nas palavras do narrador Adonias, ou ainda, como observou o primo Davi, portadores de uma bagagem de angústia e indefinição, sempre a contemplar territórios desconhecidos.

Assim, se utilizarmos as reflexões de Édouard Glissant, é possível afirmar que o reencontro com as origens sertanejas ressignificadas permitiu aos protagonistas de Galileia o abandono da certeza unitária do "ser" e a consequente aceitação de sua constante e inevitável metamorfose identitária, reconvertendo-se em "sendo", de forma fluída e aberta. Ora, aqueles sujeitos não eram mais os mesmos, tampouco o sertão, daí o estranhamento característico do trânsito na pós-modernidade.

\section{CONSIDERAÇÕES FINAIS}

O capítulo final do romance narra o retorno de Adonias, desta vez sem a companhia dos primos, tomado de arrependimento por ter se deslocado até a fazenda do avô. No entanto, a ânsia de chegar a Recife se esvai quando ao adentrar uma pequena festa popular a caminho do aeroporto, o médico acaba embriagando-se e divagando sobre "as vozes sertanejas" que o chamam constantemente 
àquele lugar. Não era possível superar o passado, menos ainda sucumbir a ele: "Não quero o Recife. Ao lado do avô e dos parentes só pensava em voltar para casa. Agora prefiro um espaço neutro" (BRITO, 2008,p.228). A neutralidade almejada por Adonias era, no entanto, irrealizável.

Entende-se, deste modo, que a leitura de Galileia permite a problematização e desconstrução da tradição narrativa a respeito do sertão nordestino, fixada, principalmente, pelos intelectuais da geração de 1930. Não se trata, no entanto, de uma negação deste legado, tampouco de uma tentativa de suplantá-lo definitivamente. Pelo contrário, o autor atualiza o olhar literário sobre o território, os povos e os costumes sertanejos, fundindo-o aos elementos de um mundo cada vez mais integrado, no qual ser e estar "neutro", como desejava o protagonista, não é uma opção. Deste movimento de contraste entre o local e o global, surgem os conflitos das personagens, que, em trânsito, evidenciam tanto a efemeridade de concepções fixas de pertencimento, quanto a inviabilidade de um discurso sobre o sertão que não desestabilize as estruturas tradicionais sobre aquela região, tais como o patriarcado e o catolicismo hegemônico.

Galileia se insere, portanto, no conjunto das obras literárias contemporâneas capazes de problematizar os fluxos migratórios internos do país, para além de suas motivações 
e desdobramentos políticos e mercadológicos. Ao enfocar os conflitos identitários decorrentes do deslocamento diaspórico, Ronaldo Correia de Brito logrou construir uma narrativa coerente com os fenômenos hodiernos catalisados pela ubiquidade promovida através das novas tecnologias. Assim, relativizou as fronteiras espaço-tempo e fez surgir um sujeito globalizado, tanto no que diz respeito à abrangência geográfica de seu trânsito, quanto à multiculturalidade inerente a este processo, já largamente teorizada pelos pesquisadores dos Estudos Culturais, e belamente ficcionalizada nas páginas de Galileia.

\section{REFERÊNCIAS}

BAUMAN, Z. (1999) Modernidade e Ambivalência. Rio de Janeiro: Jorge Zahar.

BHABHA, Homi K. (1998) O local da cultura. Belo Horizonte: UFMG. BRITO, Ronaldo Correia de. (2008). Galileia. Rio de Janeiro: Objetiva. CANCLINI, N. G. (2003). Culturas híbridas. 4. ed. São Paulo: Edusp. COSER, Stelamaris (2005). "Híbrido, Hibridismo e Hibridação". In: FIGUEIREDO, Eurídice (org.). Conceitos de Literatura e Cultura. Juiz de Fora: UFJF.

HALL, Stuart (2002). Da diáspora: identidades e mediações. Belo Horizonte: UFMG.

IBGE - INSTITUTO BRASILEIRO DE GEOGRAFIA E ESTATÍSTICA (2001). Anuário estatístico do Brasil. Rio de Janeiro: IBGE, 2001. In https:// biblioteca.ibge.gov.br/visualizacao/periodicos/20/aeb_2016.pdf. Acesso em 18.Jul.2017. 
MELO, José Inácio Vieira de. (2005)." Ronaldo Correia de Brito - O código do livro dos homens". Jornal Tribuna Feirense, Feira de Santana, 17 jun. In http://www.jornaldepoesia.jor.br/jinacio18.html. Acesso em 12.Jul.2017. MONDARDO, Marcos Leandro (2000). Contrageografias da globalização: Fronteiras Internas, Identidades em trânsito e Experiência "fora do lugar". In www.bocc.ubi.pt/pag/bocc-mondardo-contrageo.pdf Acesso em 18.Jul.2017.

PEREIRA, Rogério (2012). "Obsessivo pela exatidão". Entrevistas. Jornal Portal Rascunho. 01. Mar, 105. In http://rascunho.com.br/obsessivo-pelaexatidao. Acesso em 12.Jul.2017.

PIEIRO, Jorge (2009). "O sertão existencialista de Ronaldo Correia de Brito". Migrações. Fortaleza, nov.

ROCHA, Enilce Albergaria (2009). "A noção de Relação em Édouard Glissant". Ipótesi - revista de estudos literários, Juiz de Fora, 6(2), 31-39, jul./dez.

SILVA, Márcia Rios da. (2012). "Na viagem pelo sertão de Galileia, outras modulações regionais". Navegações, Porto Alegre, 5(2), 134-142, jul./dez.

Daniela Barbosa de Oliveira é Mestra em História e Doutoranda em Estudos Literários pela UFJF. E-mail: dani_oliveira_dani@hotmail.com. 